\title{
Characterisation of novel strains of multiply antibiotic-resistant Salmonella recovered from poultry in Southern Senegal
}

\author{
Michel M. Dione ${ }^{1}$, Stanny Geerts ${ }^{2}$ and Martin Antonio ${ }^{1}$ \\ ${ }^{1}$ Vaccinology Theme, Medical Research Council, Unit, Banjul, The Gambia \\ ${ }^{2}$ Institute of Tropical Medicine, Antwerp, Belgium
}

\begin{abstract}
Introduction: Non-typhoidal Salmonella (NTS) contamination in poultry and poultry products is a major cause of food-borne disease in humans. This study presents the molecular epidemiology of NTS isolated from poultry in Senegal.

Methodology: A total of 261 NTS recovered from broiler farms, chicken carcasses and street vendors were characterized using random amplification of polymorphic DNA (RAPD) and multilocus sequence typing (MLST) techniques.

Results: We observed 20 distinct RAPD profiles corresponding to 18 different serotypes. Strains from each of these 20 groups were further analysed using MLST. Consequently, 12 new MLST alleles and 17 new sequence types were discovered. Three sequence types (S. Kentucky ST198, S. Agona ST13 and S. Istanbul ST33) have previously been described in Senegal and other countries, suggesting that these clones are geographically widely distributed and are circulating in a wide range of hosts. Nine clones showed multi-resistance to the most commonly used antibiotics in both humans and animals. However, a novel multi-resistant clone of $S$. Kentucky ST832 was found.

Conclusion: This study gives new insights into the genetic diversity of NTS in Senegal. Molecular tools remain essential to improve our understanding of the epidemiology of NTS by tracking the sources of infection and/or contamination.
\end{abstract}

Key words: Salmonella; clones; antibiotic-resistant; Senegal

J Infect Dev Ctries 2012; 6(5):436-442.

(Received 31 August 2010 - Accepted 25 July 2011)

Copyright (C) 2012 Dione et al. This is an open-access article distributed under the Creative Commons Attribution License, which permits unrestricted use, distribution, and reproduction in any medium, provided the original work is properly cited

\section{Introduction}

Enteric diseases caused by Salmonella in chickens are of great concern because they are an important cause of mortality and morbidity [1]. Poultry and its products, in particular chicken meat and eggs, are a major source of Salmonella infection [2]. In Senegal, several studies have reported the presence of Salmonella along the poultry production supply chain and its public health impact [3-7], withserotyping being used to characterise the Salmonella [8]. Due to the ubiquitous nature of Salmonella, a typing scheme capable of a more detailed strain identification is essential for epidemiological studies [9], because the ability to distinguish isolates of Salmonella is very important to trace the source of infection and outbreaks. Several methods have been used for deciphering the relatedness among isolates but some have low discriminating power, whereas others demand a considerable amount of expertise, time and equipment [10]. Multilocus sequence typing (MLST) was found to have a low discriminative power, but is easier to interpret and to compare between laboratories and provides the best phylogeneticrelationship inferences [11]. Our study reports for the first time in Senegal the characterization of the most prevalent NTS strains isolated from poultry and poultry products by using the random amplification of polymorphic DNA (RAPD) and MLST techniques.

\section{Methodology}

Bacterial isolates

From October 2007 to July 2008, a total of 261 strains of Salmonella were collected during a crosssectional study in 57 broiler farms, 285 chicken carcasses from farms/sale points, and 42 dishes of chicken meat from street restaurants in southern Senegal [7]. Salmonella was cultured according to the standard technique ISO 6579 (1998, International Organization for Standardization, Geneva, Switzerland). Serotyping was done by slide agglutination using Salmonella polyvalent and monovalent $\mathrm{O}$ and $\mathrm{H}$ antisera (Diagnostic Pasteur, Paris, France) according to the Kauffmann-White classification scheme [8]. The data of the 
antimicrobial resistance tests were extracted from a previous study [7].

\section{$R A P D-P C R$ reaction conditions}

The RAPD reaction was performed on all 261 isolates using P1254 primer as previously described [12]. The reaction was as follows: $3 \mu 1$ of primer $(20$ $\mathrm{mM}$ ) was added to $10 \mu \mathrm{l}$ of DNA free water (Invitrogen, Paisley, UK), $5 \mu 1$ of $5 x$ Buffer (Qiagen, Crawley, UK), $2 \mu \mathrm{l}$ of dNTPS $(2 \mathrm{mM})$, and $3.5 \mu \mathrm{l}$ of $\mathrm{MgCl} 2$ (25 mM), 0.5 GoTaq polymerase (Promega, Madisson, UK) and $1 \mu 1$ of template (cells) to get the final volume of $25 \mu \mathrm{l}$. Amplification was performed in a PCR machine (Techne, Hatboro, USA) as follows: one cycle at $94^{\circ} \mathrm{C}$ ( 2 minutes); a series of 3 cycles at $94^{\circ} \mathrm{C}$ ( 2 minutes $), 35^{\circ} \mathrm{C}(1$ minute $)$ and $72^{\circ} \mathrm{C}$ ( 2 minutes); a second series of 34 cycles at $94^{\circ} \mathrm{C}(10$ seconds), $40^{\circ} \mathrm{C}$ (20 seconds) and $72^{\circ} \mathrm{C}$ (2 minutes); with final extension at $72^{\circ} \mathrm{C}$ for 5 minutes. The amplified product was stored at $4^{\circ} \mathrm{C}$ until required. The PCR product (10 $\mu 1$ each) was loaded on a $1.5 \%$ agarose gel containing $0.5 \mathrm{ul} / \mathrm{ml}$ ethidium bromide at $25 \mathrm{~V}$ overnight in $1 \mathrm{X}$ (SIGMA, Steinheim, Germany). Two lanes of $50 \mathrm{bp}$ and $100 \mathrm{bp}$ of ladder were included in each gel for reference. The RAPD electrophoresis bands were photographed using UV illumination with a gel documentation system (gel Doc 2000, Bio-Rad, Hertfordshire, UK). Gel pictures were analysed with Bionumerics software (version 4.0; Applied Maths, Saint-Martens-Latem, Belgium) and finally similar profiles resolving into similar clones were selected.

\section{Multi locus sequence typing}

MLST was performed on 20 randomly selected Salmonella serotypes with unique RAPD profiles. The protocol was followed as previously described [13] . Briefly, the seven genes were targeted were aroC, dnaN, hemD, hisD, purE, sucE and thrA. Amplification of all genes was performed with a 25 $\mu 1$ reaction mixture of the following: 10x Buffer (Applied Biosystems, Foster City, USA) with $1.5 \mathrm{mM}$ $\mathrm{MgCl}_{2}(2.5 \mu \mathrm{l}) ; 2 \mathrm{mM}$ dNTP $(0.5 \mu \mathrm{l}) ; 12.5 \mathrm{mM}$ forward primer $(1 \mu \mathrm{l}) ; 12.5 \mathrm{mM}$ reverse primer $(1$ $\mu 1) ; 5 \mathrm{U} / \mu \mathrm{l}$ Qiagen Hotstart Taq Polymerase (Qiagen, Crawley, UK) $(0.25 \mu \mathrm{l})$; template (cell lysate) $(2 \mu \mathrm{l})$ and $17.75 \mu 1$ sterile DNA free water. PCR cycling conditions were 10 minutes at $94^{\circ} \mathrm{C}$, followed by 32 cycles of $94^{\circ} \mathrm{C}$ for 1 minute, $55^{\circ} \mathrm{C}$ for 1 minute and $72^{\circ} \mathrm{C}$ for 1 minute, with a final extension at $72^{\circ} \mathrm{C}$ for 5 minutes. From each PCR, $2 \mu 1$ aliquots were separated by $1 \%$ agarose gel electrophoresis and visualized with ethidium bromide staining and UV illumination, and using a gel documentation system (gel Doc 2000, Bio-Rad, Hertfordshire, UK). PCR products were purified using Qiagen kit (Qiagen, Crawley, UK). Sequencing was done on both strands with BigDye Terminator Cycle Sequencing kit (Applied Biosystems, Warrington, UK). The labelled fragments were separated by size using a 3130xl Genetic Analyser (Applied Biosystems, UK). Sequences were edited and complementary sense antisense fragments were aligned using the Laser Gene DNA star 7.1 software. Finally, the sequences were submitted to the MLST database website [14] and assigned to existing or novel allele type numbers defined by the database. New sequence types were arbitrarily assigned a number for the purpose of the analysis.

\section{Cluster analysis and mapping}

To perform the cluster analysis of the serotypes, MLST data were analysed with Bionumerics software (version 6.5; Applied Maths, Sint-MartensLatem, Belgium). Analysis using a hierarchic unweighted pair group method (UPGMA) with averaging was used to generate a dendrogram describing the relationship among Salmonella serotypes. A minimum spanning tree was used to compare Senegalese clones to Gambian and other African clones. The mapping of the locations of the cases was performed using Arc Gis 9.3 software.

\section{Results}

In this study, we analyzed the genomic relatedness between 261 NTS belonging to 18 different serovars, initially using RAPD profiling. All RAPD fragments amplified were between $200 \mathrm{bp}$ and 3000 bp. Twenty different RAPD fingerprints were observed among the 261 NTS (Figure 1). Each serovar generated a unique RAPD fingerprints, with the exception of two serovars, $S$. Javiana (Figure 1, lanes 14 and line 15) and S. Kentucky (Figure 1, lanes 16 and line 17) which each showed two different fingerprints. To further characterise these NTS, MLST was performed on one strain from each unique RAPD type. Twelve new alleles were discovered [aroC (203), aroC (204), aroC (205), dnaN (195), dnaN (196), hisD (238), hisD (239), hisD (241), purE (199), sucA (195), thrA (185), and thrA (186)] as well as sixteen new sequence types (ST923, ST824, ST825, ST826, ST827, ST828, ST829, ST830, ST831, ST832, ST833, ST834, 
Table 1. Multilocus Sequence Typing of Salmonella serotypes and antibiotic resistance patterns

\begin{tabular}{|c|c|c|c|c|c|c|c|c|c|c|c|}
\hline & & & & & 1lele nu & nber & & & & & \\
\hline Strain ID & Serotype & aroC & $\operatorname{dnaN}$ & hemD & hisD & purE & sucA & $\operatorname{thr} A$ & ST & Source (chicken) & Antibiotic resistance \\
\hline A1001 & Agona & 3 & 3 & 7 & 4 & 3 & 3 & 7 & 13 & skin & SPT \\
\hline A1002 & Bandia & 84 & 65 & 8 & 241 & 64 & 9 & 168 & $\underline{823}$ & stool & STX, TMP, CIP, SSS \\
\hline A1003 & Bessi & $\underline{204}$ & 11 & 8 & $\underline{241}$ & 161 & $\underline{195}$ & $\underline{186}$ & $\underline{824}$ & skin & None \\
\hline A1004 & Brancaster & 205 & 81 & 10 & 36 & 88 & 108 & 36 & $\underline{825}$ & skin & STX, TE, TMP, S, SSS \\
\hline A1005 & Brunei & 19 & 81 & 8 & 20 & 5 & 9 & 185 & $\underline{826}$ & stool & AMX, TIC, STX, TE, TMP, SSS \\
\hline A1006 & Sp. & 203 & 195 & 17 & 164 & 12 & 35 & 4 & $\underline{827}$ & skin & SPT \\
\hline A1007 & Hadar & 17 & 5 & 78 & 7 & 5 & 7 & 12 & $\underline{828}$ & muscle & STX, TE, TMP, S, SSS \\
\hline A1008 & Hull & 114 & 5 & 3 & 238 & 199 & 10 & 12 & $\underline{829}$ & skin & None \\
\hline A1009 & Istanbul & 2 & 5 & 6 & 7 & 5 & 7 & 12 & 33 & restaurant & CF, STX, TE, GM, TMP, SPT, S, SSS \\
\hline A1010 & Javiana & 11 & 196 & 78 & 74 & 40 & 13 & 4 & $\underline{830}$ & skin & None \\
\hline A232 & Javiana & 11 & 196 & 78 & 74 & 40 & 13 & 4 & $\underline{830}$ & muscle & None \\
\hline A1011 & Kentucky & 76 & 14 & 3 & 77 & 64 & 64 & 67 & 198 & skin & None \\
\hline A112 & Kentucky & 115 & 65 & 8 & 115 & 2 & 116 & 110 & $\underline{832}$ & stool & STX, TMP, SPT, S, SSS \\
\hline A1012 & Magherafelt & 84 & 65 & 3 & 241 & 64 & 9 & 110 & $\underline{833}$ & skin & None \\
\hline A1013 & Sp. & 76 & 14 & 3 & 77 & 64 & 132 & 67 & $\underline{835}$ & skin & STX, TE, TMP, SPT, S, SSS \\
\hline A1014 & Sp. & $\underline{203}$ & 14 & 17 & 164 & 12 & 35 & 4 & $\underline{836}$ & skin & None \\
\hline A1015 & Poona & 13 & 127 & 92 & 157 & 40 & 35 & 137 & $\underline{838}$ & skin & AMX, TIC, STX, TE, TMP, SPT, S, SSS \\
\hline A1016 & Rubislaw & 42 & 46 & 48 & $\underline{239}$ & 12 & 35 & 4 & $\underline{837}$ & stool & None \\
\hline A1017 & Tamale & $\underline{205}$ & 46 & 8 & 42 & 88 & 108 & 36 & $\underline{834}$ & stool & STX, TE, TMP, SPT, S, SSS \\
\hline A1018 & Zanzibar & 84 & 11 & 8 & 42 & 40 & 71 & 4 & $\underline{831}$ & muscle & SPT, S \\
\hline
\end{tabular}

ST: sequence type, The underlined numbers are the new alleles and STs discovered in this study.

AMX, amoxicillin; TIC, ticarcillin; CF, ciprofloxacin cephalotin; STX, trimethoprim plus sulfamethoxazole; TE, tetracycline; C, chloramphenicol; GM, gentamicin; TMP, trimethoprim; CIP, ciprofloxacin; SPT, spectinomycin; S, streptomycin; SSS, sulfonamides 
Figure 1. RAPD profiles of 25 Salmonella serotypes

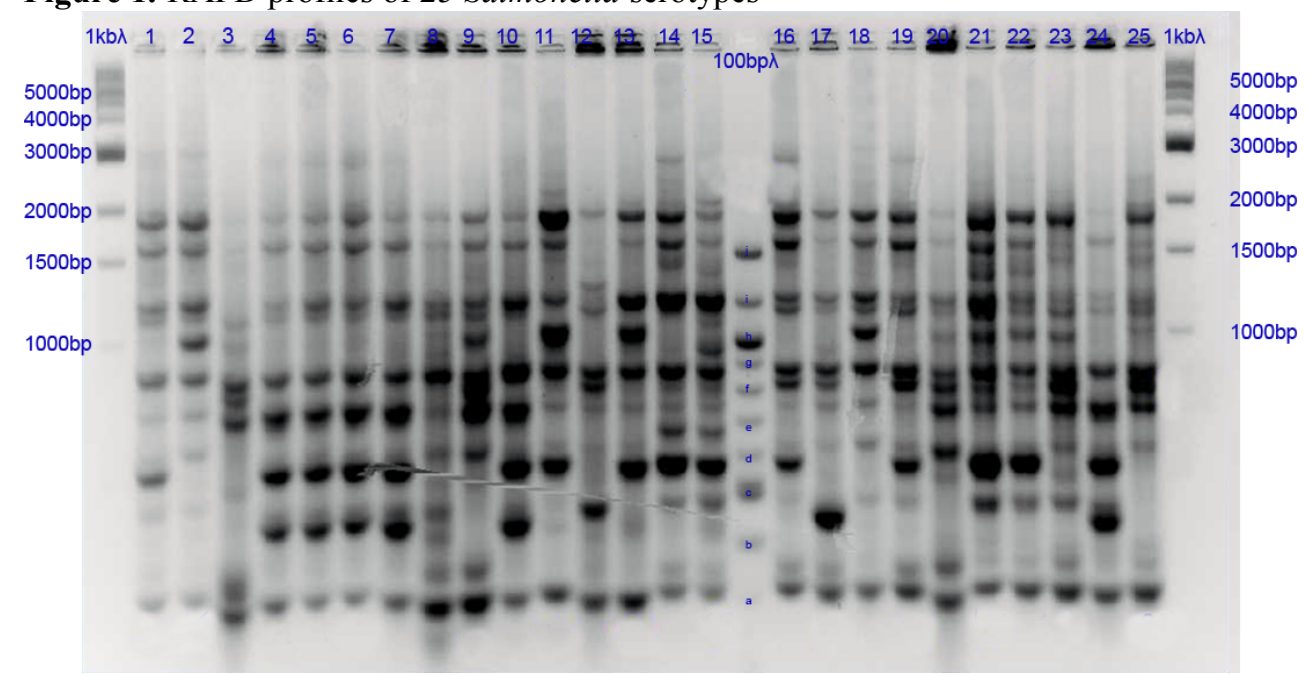

Lanes: $S$. Agona (1), S. Bandia (2), S. Bessi(3), S. Brancaster (4, 5, 6, 7), S. Brunei (8), Sp (9, 10), S. Hadar (11), S. Hull (12), S. Istanbul (13), S. Javiana $(14,15), S$. Kentucky (16, 17), S. Magherafelt (18), S. Molade (19), S. Oxford (20), ) S. Poona (21, 22), S. Rubislaw (23), S. Tamale (24), S. Zanzibar (25) 100 bp ladder: a (300 bp), b (400 bp), c (500 bp), d (600 bp), e (700 bp), f (800 bp), g (900 bp), h (1000 bp), i (1200 bp), j (1517 bp)

ST835, ST836, ST837, ST838), giving a total of 19 different STs in the 20 strains (Table 1). The strains characterised belong to three clusters showing a DNA identity of 98.8 to $100 \%$ at MLST loci. Most of the antibiotic sensitive strains belonged to a different cluster from that containing predominantly resistant strains (Figure 2). The Senegalese and Gambian serovars cluster together and these are derived from the ST19, ST626 and ST937 clonal complexes (Figure 3).

Interestingly, both $S$. Javiana RAPD types belonged to the same novel sequence type (ST830) while both $S$. Kentucky RAPD types had different ST (ST198 and ST832). Ten of the strains tested were resistant to multiple antibiotics, with two resistant just to spectinomycin and eight strains were fully susceptible to all tested antibiotics (Table 1).

\section{Discussion}

Salmonella is frequently isolated from poultry products in Senegal as shown by several studies [34,6] and confirmed in our previous study [7], with serotypes $S$. Brancaster, $S$. Hadar, $S$. Kentucky, and $S$. Agona found most commonly in poultry and poultry products.

RAPD profiling has been widely used to assess the genetic relatedness between Salmonella isolates indicating the reliable discriminatory power of this technique in subdividing strains within serotypes [1,10,12,15-16]. MLST has also been considered a method of choice for detailed characterization of a number of pathogens [14,17-18]. Although some authors have reported that MLST is not suitable to distinguish between closely related strains within the same serotype [19-20],in this study we showed that MLST is able to distinguish strains belonging to the same serotype, as in the case with the two $S$. Kentucky serotypes. Furthermore, both MLST and RAPD provided subtypes for $S$. Kentucky, meaning that MLST and RAPD techniques are more distinctive than serotyping for $S$. Kentucky; this result concurs with those of other studies that showed that MLST was more sensitive than serotyping [2122]. The $S$. Kentucky ST198 and $S$. Kentucky ST 832 did not share any alleles and while the former was fully susceptible to all antibiotics, the latter was multi-resistant to four antibiotics.

The high genetic similarity among serovars is not surprising as the clones were sampled from poultry farms in the same geographic urban area in Southern Senegal. The antibiotic sensitive strains cluster together and have been shown to belong to a new set of strains which is not frequently isolated in poultry in Senegal [7], Their high rate of sensitivity could be explained by the fact that they have not yet been under stress (antibiotic treatment) and thus have not adapted themselves to the environment by acquiring resistance determinants [24].

The currently accepted "gold standard" for the characterization of NTS is PFGE, and this, along with other methods such as plasmid profiling, could also be used to determine the diversity of isolates within this study. $S$. Kentucky ST198 has been 
Figure 2. UPGMA dendrogram based on the similarity matrix showing the relationship between the concatenated seven housekeeping gene fragments from 20 Salmonella

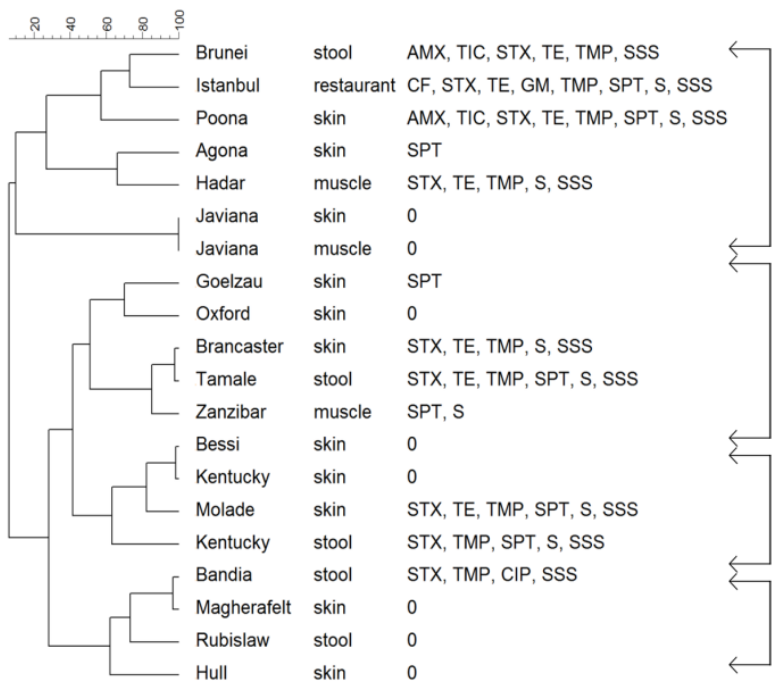

Figure 3: Clustering of STs using minimum spanning tree

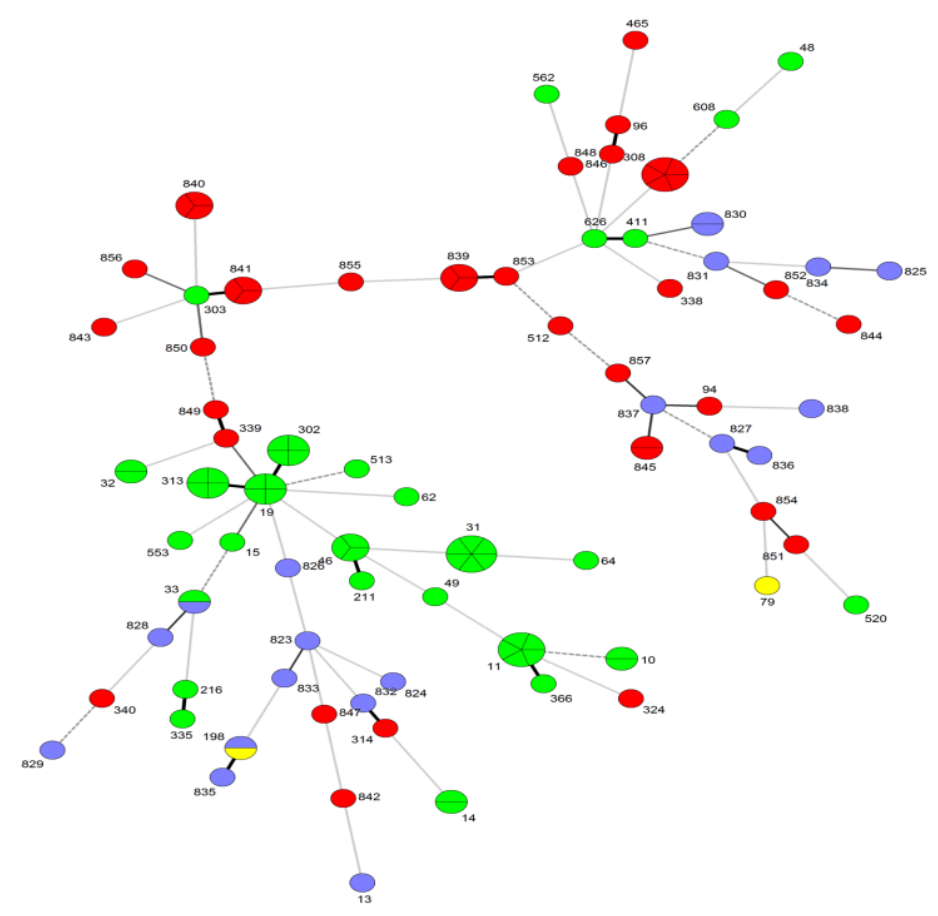

Each circle represents an ST. The area of each circle corresponds to the number of isolates. The length of the lines represents the number of locus variants. Thick, short, solid lines connect single locus variants; thick longer solid lines connect double-locus variants; thin long solid connect to 3 locus variants; dashed connect to 4 locus variants and dotted connect to 5 locus variants. Violet portions represent the Senegalese STs described in this study; Yellow portions represent Senegalese STs described earlier to this study; red portions represent Gambian STs and green portions represent STs found in the rest of the world. 
previously isolated from humans in Senegal and from food and cattle in the United States (USA). Our study revealed its presence in chicken skin in southern Senegal. S. Agona ST13 found in chicken skin in our study was also previously described in Denmark from both human and veterinary sources, from milk in Ireland, from humans in Scotland, and from undetermined hosts in Australia, Germany, the USA, Canada and Spain [23], while S. Hadar ST33 was isolated from various sources in several European and American countries and South Africa [23]. However, the ST33 found in southern Senegal in our study belonged to serovar $S$. Istanbul. Collectively, ST13, ST33 and ST198 clones are widely distributed throughout the world and all three clones have been simultaneously identified in both human and animal sources, suggesting that the same clones are circulating in both hosts. $S$. Istanbul ST33 was multiresistant to most commonly used antibiotics in humans and animals in southern Senegal, contrary to $S$. Kentucky ST198 and S. Agona ST13, which were fully sensitive to all antibiotics tested. However, a novel multi-resistant clone of $S$. Kentucky ST832 was found in poultry.

\section{Conclusion}

Our study showed that a variety of serovars and clones is circulating in southern Senegal; furthermore, 17 out of the 20 clones characterised in this study have never been reported elsewhere in the world.

This is the first report describing the use of MLST to characterise the most common NTS in poultry and poultry products in Senegal. The discovery of new alleles and sequence types is very useful for a better understanding of the epidemiology of NTS in Senegal.

\section{Acknowledgments}

This work was supported by the Flemish Interuniversity Council (VLIR-UOS, Brussels, Belgium) and the Medical Research Council, United Kingdom. We acknowledge Mark Achtman for the use of the Salmonella MLST database (http://mlst.ucc.ie/mlst/dbs/Senterica), which is hosted at the University College Cork and funded by the Science Foundation of Ireland (05/FE1/B882).

\section{References}

1. Chansiripornchai N, Ramasoota P, Bangtrakulnonth A, Sasipreeyajan J, Svenson SB(2000) Application of randomly amplified polymorphic DNA (RAPD) analysis for typing
Avian Salmonella enterica subsp. enterica. FEMS Immunol Med Microbiol 29: 221-225.

2. Rampling A (1993) Salmonella enteritidis five years on. Lancet 342: 317-318.

3. Bada-Alambedji R, Fofana A, Seydi M, Akakpo AJ (2006) Antimicrobial resistance of Salmonella isolated from poultry carcasses in Dakar (Senegal). Braz J Microbiol 37: 510-515.

4. Cardinale E, Perrier Gros-Claude JD, Tall F, Cisse M, Gueye EHF, Salvat G (2003) Prevalence of Salmonella and Campylobacter in retail chicken carcasses in Senegal. Rev Elev Vét Pays Trop 56: 13-16.

5. Cardinale E, Perrier Gros-Claude JD, Tall F, Gueye EF, Salvat G (2005) Risk factors for contamination of ready-toeat street-vended poultry dishes in Dakar, Senegal. Int J Food Microbiol 103: 157-65.

6. Cardinale E, Tall F, Gueye, EF, Cisse M, Salvat G (2004) Risk factors for Salmonella enterica subsp. enterica infection in Senegalese broiler-chicken flocks. Prev VetMed 63: 151-161.

7. Dione MM, Ieven M, Garin B, Marcotty T, Geerts S (2009) Prevalence and antimicrobial resistance of Salmonella isolated from broiler farms, chicken carcasses, and streetvended restaurants in Casamance, Senegal. J Food Prot 72: 2423-2427.

8. Grimont PAD, Weill FX (2007) Antigenic formulae of the Salmonella serovars. 9th Edition. WHO Collaboration Centre for Reference and Research on Salmonella and Institut Pasteur, 167p.

9. Betancor LF, Schelott A, Martinez M, Pereira G, Algorta MA, Rodrigez F, Vignoli Chabalgoity JA (2004) Random Amplified Polymorphic DNA and phenotyping analysis of Salmonella enterica serovar enteritidis isolates collected from humans and poultry in Uruguay from 1995-2002. J Clin Microbiol 42: 1155-1162.

10. Maripandi A, Suresh SSR, Ponmurugan P, Gurusubramanian G (2007) Random Amplification of Polymorphic DNA (RAPD) of Salmonella enteritidis Isolated from Chicken Samples. Biotechnology 6: 278-282.

11. Cooper JE, Feil EJ (2004) Multilocus sequence typing-what is resolved? . Trends Microbiol 12: 373-377.

12. Lin AW, Usera MA, Barrett TJ, Goldsby RA (1996) Application of random amplified DNA analysis to differentiate strains of Salmonella enteritidis. J Clin Microbiol34: 870-876.

13. Ikumapayi UN, Antonio M, Sonne-Hansen J, Biney E, Enwere G, Okoko B, Oluwalana C, Vaughan A, Zaman SM, Greenwood BM, Cutts FT, Adegbola RA (2007) Molecular epidemiology of community-acquired invasive nontyphoidal Salmonella among children aged 2-29 months in rural Gambia and discovery of a new serovar, Salmonella enterica Dingiri. J Med Microbiol 56: 1479-1484.

14. Aanensen DM and Spratt BG (2005) The multilocus sequence typing network: mlst.net Nucleic Acids Res. 33: 728-733.

15. Tikoo A, Tripathi AK, Verma SC, Agrawal N, Nath G (2001) Application of PCR finger printing techniques for identification and discrimination of Salmonella isolates. Curr Sci. 80: 1049-1052.

16. Yaqoob E, Hussain I, Rahman SU (2007) Molecular characterization by using amplified polymorphic DNA (RAPD) analysis of Salmonella enteritidis isolates recovered from avian and human sources. Pakistan Vet J 27: 102-104.

17. Torpdahl M, Skov MN, Sandvang D, Baggesen DL (2005) Genotypic characterization of Salmonella by multilocus 
sequence typing, pulsed-field gel electrophoresis and amplified fragment length polymorphism. J Microbiol Methods 63: 173-184.

18. Urwin R and Maiden MC (2003) Multi-locus sequence typing: a tool for global epidemiology. Trends Microbiol 11: 479-487.

19. Ross IL and Heuzenroeder MW (2004) Discrimination within phenotypically closely related definitive types of Salmonella enterica Serovar Typhimurium by the multiple amplification of phage locus typing technique. J Clin Microbiol 43: 1604-1611.

20. Sukhnanand S, Alcaine S, Warnick LD, Su WL, Hof J, Craver MP, McDonough P, Boor KJ, Wiedmann M (2005) DNA sequenced-based subtyping and evolutionary analysis of selected Salmonella serotypes. J Clin Microbio 43: 36883698 .

21. Alcaine SD, Soyer Y, Warnick LD, Su WL (2006) Multilocus sequence typing supports the hypothesis that cow- and human-associated Salmonella isolates represent distinct and overlapping populations. Appl Environ Microbiol 72: 7575-7585.

22. Kotetishvili M, Stine OC, Kreger A, Morris JG, Jr Sulakvelidze A (2002) Multilocus sequence typing for characterization of clinical and environmental Salmonella strains. J Clin Microbiol 40: 1626-35.

23. MLST, multilocus sequence typing website. Available: http://www.mlst.net. Accessed June 2010.

24. Martinez ZL and Baquero F (2002) Interaction among strategies associated with bacterial infection: pathogenicity, epidemicity, and antibiotic resistance. Clin Microb Rev 15: 647-679.

\section{Corresponding author}

Dr Martin Antonio

Medical Research Council Unit

Banjul, The Gambia

Telephone: + 22044954 42; Fax: + 2204495919

Email: mantonio@mrc.gm

Conflict of interests: No conflict of interests is declared. 